\title{
Camurati-Engelmann disease combined with transethmoidal meningoencephalocele: illustrative case
}

\author{
Wataru Yanagihara, MD, Tsukasa Wada, MD, Jun-ichi Nomura, MD, Hiroaki Saura, MD, Yoshitaka Kubo, MD, and \\ Kuniaki Ogasawara, MD
}

Department of Neurosurgery, Iwate Medical University School of Medicine, Iwate, Japan

BACKGROUND Camurati-Engelmann disease (CED) is a rare disorder characterized by progressive cranial hyperostosis and diaphyseal sclerosis of the long bones. Chronic intracranial hypertension gradually occurs due to progressive cranial vault hyperostosis.

OBSERVATIONS A 57-year-old man who had been diagnosed with CED at 9 years old suddenly developed cerebrospinal fluid rhinorrhea. A bone defect of the right cribriform plate and protrusion of brain tissue from the right cribriform plate into the right nasal cavity were identified. The patient underwent endoscopic resection of the meningoencephalocele combined with the bath-plug procedure. After surgery, cerebrospinal fluid rhinorrhea disappeared.

LESSONS Chronic intracranial hypertension due to progressive cranial vault hyperostosis in CED may cause a bone defect and meningoencephalocele in the anterior skull base, resulting in cerebrospinal fluid rhinorrhea.

https://thejns.org/doi/abs/10.3171/CASE21587

KEYWORDS Camurati-Engelmann disease; meningoencephalocele; intracranial hypertension

Camurati-Engelmann disease (CED) is a disorder characterized by progressive cranial hyperostosis and diaphyseal sclerosis of the long bones; only approximately 300 cases of CED have been reported. ${ }^{1}$ Chronic intracranial hypertension gradually occurs due to progressive cranial vault hyperostosis. ${ }^{1}$ We report a case of a patient with CED combined with transethmoidal meningoencephalocele.

\section{Illustrative Case}

A 57-year-old man who had been diagnosed with CamuratiEngelmann disease (CED) at 9 years of age based on a marfanoid body, pain in the extremities, and fusiform-shaped cortical thickening of the diaphysis of the extremities suddenly developed cerebrospinal fluid (CSF) rhinorrhea. He also experienced a gradual decline in bilateral visual acuity at 27 years old and underwent realignment surgery for knock knee at 29 years old. His cousin was also diagnosed with CED.

At the visit to our hospital, serous rhinorrhea was observed when the neck was flexed. Neurological examinations showed defects in the visual field except the central visual field in the bilateral eyes. Fundoscopy showed optic nerve atrophy in the bilateral eyes. To measure intracranial pressure and rule out meningitis, CSF examination was performed via lumbar puncture: the opening pressure was $35 \mathrm{~cm} \mathrm{H}_{2} \mathrm{O}$; the fluid was watery and clear; and the number of cells was within the normal limit.

Intranasal endoscopic examination revealed a meningoencephalocele and CSF rhinorrhea in the right nasal cavity (Fig. 1). Magnetic resonance imaging (MRI) showed brain tissue protruding from the right cribriform plate into the right nasal cavity (Fig. 2). Cranial computed tomography displayed marked hypertrophy of the calvaria and the lateral part of the skull base (Fig. 3). The left cribriform plate was normal, and a defect $14 \times 8 \mathrm{~mm}$ was observed in the right cribriform plate (Fig. 3).

A right endonasal endoscopic approach was performed under general anesthesia to treat the CSF rhinorrhea. First, the brain tissue protruding into the right nasal cavity was resected. Next, the defect in the right cribriform plate was closed with the bathplug

ABBREVIATIONS CED = Camurati-Engelmann disease; $\mathrm{CSF}=$ cerebrospinal fluid; $\mathrm{MRI}=$ magnetic resonance imaging INCLUDE WHEN CITING Published February 28, 2022; DOI: 10.3171/CASE21587.

SUBMITTED October 14, 2021. ACCEPTED January 14, 2022.

(C) 2022 The authors, CC BY-NC-ND 4.0 (http://creativecommons.org/licenses/by-nc-nd/4.0/). 


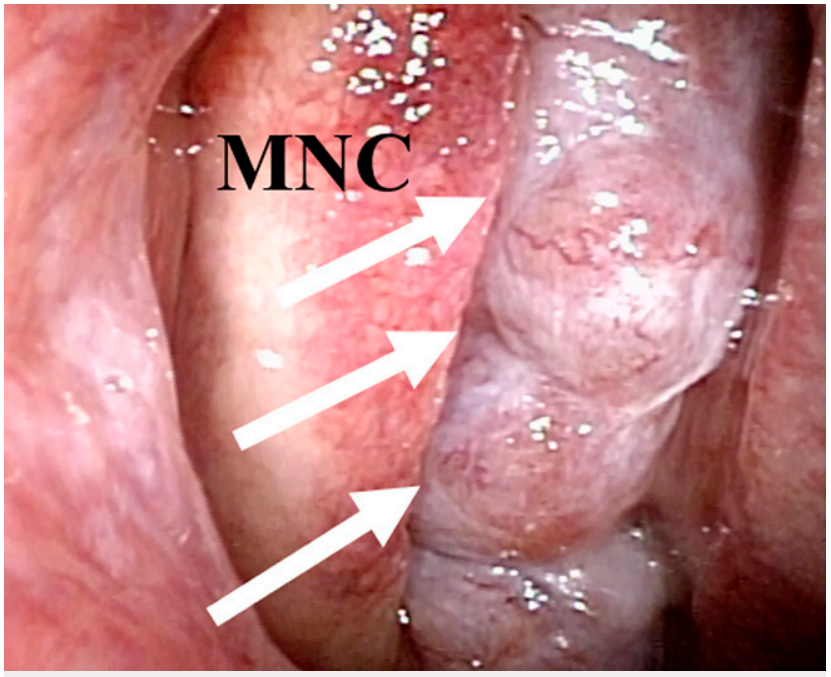

FIG. 1. Intranasal endoscopic examination reveals a meningoencephalocele (arrows) in the right nasal cavity. MNC = middle nasal concha.

procedure $^{2,3}$ as follows: an absorbable suture was fixed to fat that was collected from the abdominal subcutaneous tissues, and the fat was inserted into the skull base through the bone defect. The suture was tagged, and the fat plug was impacted into the bone defect. After cutting the suture, the defect in the nasal cavity was covered with mucosa in the nasal septum.

The postoperative course was uneventful, and the CSF rhinorrhea disappeared. The patient received acetazolamide $500 \mathrm{mg} /$ day after surgery to control intracranial pressure. ${ }^{1}$ MRI 3 months after surgery showed resolution of the meningoencephalocele (Fig. 4), and CSF rhinorrhea did not recur.

\section{Discussion}

\section{Observations}

The present patient with CED developed transethmoidal meningoencephalocele with CSF rhinorrhea. Such a case has not been previously reported. In CED, transforming growth factor $\beta 1$ activity is increased due to a mutation in TGFB1, which is in chromosomal region $19 q 13 .{ }^{4-6}$ As a result, intramembranous ossification is activated, and bone resorption is inhibited. ${ }^{7}$ CED presents as pain in
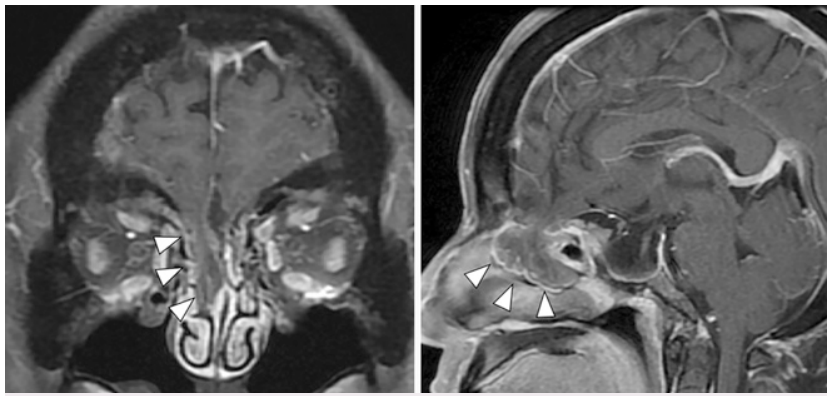

FIG. 2. MRI (left, coronal image; right, sagittal image) show brain tissue protruding from the right cribriform plate into the right nasal cavity (arrowheads).
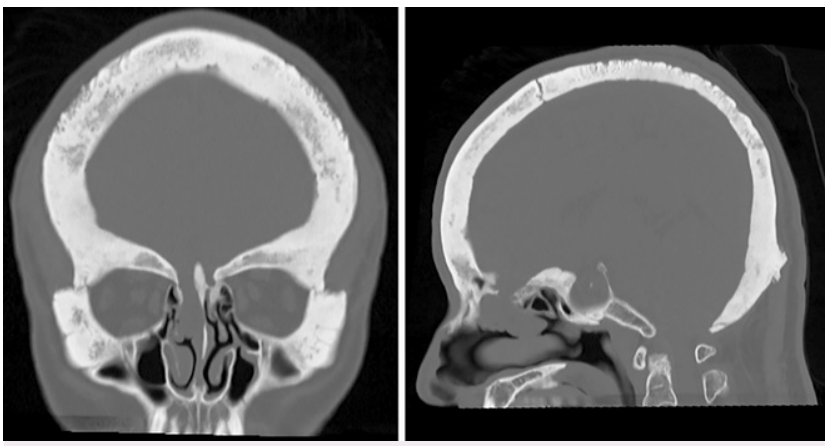

FIG. 3. Cranial computed tomograms (left, coronal image; right, sagittal image) display marked hypertrophy of the calvaria and the lateral part of the skull base and a bone defect in the right cribriform plate.

the extremities, marfanoid body habitus, and proximal muscle weakness on physical examination, and cortical thickening of the diaphysis of the long bone on radiological imaging. ${ }^{8}$ Furthermore, intracranial pressure is elevated due to progressive cranial vault hyperostosis, and the cranial base foramina are compressed due to hyperostosis of the lateral cranial base, resulting in cranial nerve palsy. ${ }^{1}$ In the present case, the patient's visual field defect may have occurred due to optic nerve atrophy caused by these two mechanisms.

\section{Lessons}

In general, chronic intracranial hypertension leads to thinning of the cranial sutures between the temporal bone, sphenoid bone, and cribriform plate, inducing herniation of the brain tissue via such cranial bones. ${ }^{9-11}$ As a result, meningoencephalocele develops in the anterior skull base. ${ }^{9-11}$ The cranial vault and the anterior skull base are essentially formed by intramembranous ossification and endochondral ossification, respectively. ${ }^{12}$ In CED, only the former is

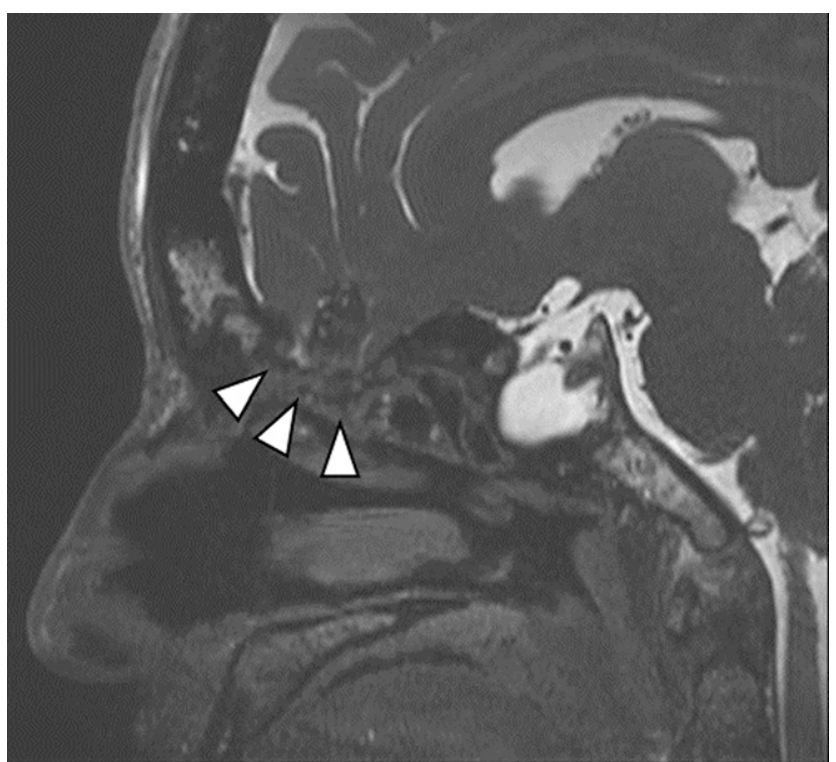

FIG. 4. MRI 3 months after surgery shows resolution of the meningoencephalocele (arrowheads). 
hypertrophic, inducing chronic intracranial hypertension. ${ }^{1,7}$ In the present patient, this situation may have led to thinning of the cribriform plate, resulting in CSF rhinorrhea and meningoencephalocele. A case of CED with meningitis was previously reported, but the presence or absence of CSF rhinorrhea or meningoencephalocele was not documented. ${ }^{13}$ Therefore, the anterior skull base should be examined for a bone defect or meningoencephalocele in patients with CED combined with meningitis.

\section{References}

1. Carlson ML, Beatty CW, Neff BA, Link MJ, Driscoll CL. Skull base manifestations of Camurati-Engelmann disease. Arch Otolaryngol Head Neck Surg. 2010;136(6):566-575.

2. Wormald PJ, McDonogh M. 'Bath-plug' technique for the endoscopic management of cerebrospinal fluid leaks. J Laryngol Otol. 1997; 111(11):1042-1046.

3. Wormald PJ, McDonogh M. The bath-plug closure of anterior skull base cerebrospinal fluid leaks. Am J Rhinol. 2003;17(5):299-305.

4. Janssens K, Gershoni-Baruch R, Guañabens N, et al. Mutations in the gene encoding the latency-associated peptide of TGF-beta 1 cause Camurati-Engelmann disease. Nat Genet. 2000;26(3): 273-275.

5. Janssens K, Gershoni-Baruch R, Van Hul E, et al. Localisation of the gene causing diaphyseal dysplasia Camurati-Engelmann to chromosome 19q13. J Med Genet. 2000;37(4):245-249.

6. Kinoshita A, Saito T, Tomita H, et al. Domain-specific mutations in TGFB1 result in Camurati-Engelmann disease. Nat Genet. 2000;26(1):19-20.

7. Greenspan A. Sclerosing bone dysplasias-a target-site approach. Skeletal Radiol. 1991;20(8):561-583.

8. Adam MP, Ardinger HH, Pagon RA, et al. GeneReviews. University of Washington; 1993-2021.
9. Cruz E Silva V, Luís A, Mora Féria R, et al. Transsphenoidal meningoencephalocele protruding into the nasal cavity. BJR Case Rep. 2016;3(2):20160082.

10. Urbach H, Jamneala G, Mader I, Egger K, Yang S, Altenmüller D. Temporal lobe epilepsy due to meningoencephaloceles into the greater sphenoid wing: a consequence of idiopathic intracranial hypertension? Neuroradiology. 2018;60(1):51-60.

11. McCorquodale D, Burton TM, Winegar B, Pulst SM. Teaching neuroimages: meningoencephalocele and CSF leak in chronic idiopathic intracranial hypertension. Neurology. 2016;87(20):e244.

12. Di leva A, Bruner E, Haider T, et al. Skull base embryology: a multidisciplinary review. Childs Nerv Syst. 2014;30(6):991-1000.

13. Hughes P, Hassan I, Que L, et al. Observations on the natural history of Camurati-Engelmann disease. J Bone Miner Res. 2019;34(5):875-882.

\section{Disclosures}

The authors report no conflict of interest concerning the materials or methods used in this study or the findings specified in this paper.

\section{Author Contributions}

Conception and design: Yanagihara, Wada, Ogasawara. Acquisition of data: Yanagihara, Wada, Nomura, Kubo, Ogasawara. Analysis and interpretation of data: Yanagihara, Wada, Kubo, Ogasawara. Drafting the article: Yanagihara, Wada, Kubo, Ogasawara. Critically revising the article: Wada. Reviewed submitted version of manuscript: Wada. Approved the final version of the manuscript on behalf of all authors: Yanagihara. Administrative/technical/material support: Saura. Study supervision: Kubo.

\section{Correspondence}

Wataru Yanagihara: Iwate Medical University School of Medicine, Iwate, Japan. yanagi@iwate-med.ac.jp. 